\title{
Comparison of response
} characteristics of high-purity germanium detectors using analog versus digital processing

Ken Raschke

S. John Luke

April 23, 2004

U.S. Department of Energy

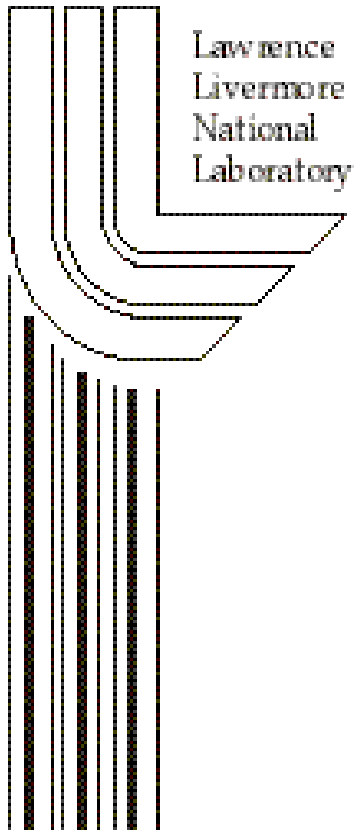




\section{DISCLAIMER}

This document was prepared as an account of work sponsored by an agency of the United States Government. Neither the United States Government nor the University of California nor any of their employees, makes any warranty, express or implied, or assumes any legal liability or responsibility for the accuracy, completeness, or usefulness of any information, apparatus, product, or process disclosed, or represents that its use would not infringe privately owned rights. Reference herein to any specific commercial product, process, or service by trade name, trademark, manufacturer, or otherwise, does not necessarily constitute or imply its endorsement, recommendation, or favoring by the United States Government or the University of California. The views and opinions of authors expressed herein do not necessarily state or reflect those of the United States Government or the University of California, and shall not be used for advertising or product endorsement purposes.

This work was performed under the auspices of the U. S. Department of Energy by the University of California, Lawrence Livermore National Laboratory under Contract No. W-7405-Eng-48.

This report has been reproduced directly from the best available copy.

Available to DOE and DOE contractors from the

Office of Scientific and Technical Information

P.O. Box 62, Oak Ridge, TN 37831

Prices available from (423) 576-8401

http: / / apollo.osti.gov/bridge /

Available to the public from the National Technical Information Service

U.S. Department of Commerce 5285 Port Royal Rd., Springfield, VA 22161

http:/ / www.ntis.gov/

OR

Lawrence Livermore National Laboratory Technical Information Department's Digital Library http:/ / www.llnl.gov/tid/Library.html 


\title{
Comparison of response characteristics of High-Purity Germanium Detectors using analog versus digital processing
}

\author{
Ken Raschke and S. John Luke \\ Lawrence Livermore National Laboratory
}

April 22, 2004

\begin{abstract}
In this acrticle we will discuss some of the results of the response characteristics of High Purity germanium detectors using analog versus digital processing of the signals that are outputted from the detector. The discussion will focus on whether or not there us a significant difference in the response of the detector with digital electronics that it limits the ability of the detection system to get reasonable gamma ray spectrometric results. Particularily, whether or not the performance of the analysis code Pu600 is compromised.
\end{abstract}

\section{Introduction}

The Lawrence Livermore National Laboratory developed plutonium isotopic system known as Pu600 has been used as a model system for the determination of plutonium isotopics of a plutonium sample. It has been the contention of the Pu600 developer group that the Pu600 system is a system and not simply a computer code. The developers of Pu600 have long argued that it is not prudent to simply install the analysis portion of the Pu600 system on a computer and perform analysis on acquired spectra. The issues which make such an approach problematic revolve mainly around the response of the gamma spectrometry system to the incident gamma ray radiation. The response of the spectrometry system is a function of the detector itself and the electronics that are used to process the data from the detector. Most of the time when the response of the detector is considered only the resolution is examined and this serves as the first order test of the response of the detection. However, to fully understand the implications of the response of the gamma ray system on the ability of an analysis package to analyze data from the system it is necessary to understand the nuances of the peak shape of the obtained pulse height distribution. This 
also introduces the complication that any discussion of the peak shape is by nature model dependent.

The best one can do is try to understand the effect of a different processing electronics on the resolution on the spectrometry system - which a quantitative measurement and then make some qualitative statements of the effects of variation of the peak parameters on the analysis package to perform a suitable evaluation of a data set. This is the approach the we take in this short paper. We will discuss the effect of using digital processing of the gamma ray signals versus standard analog electronics. After which we will make qualitative observations of the effect of digital processing on the nature of the peak in the observed pulse height distribution. Finally, we will give some recommendations for using Pu600 with the newer digital analysis systems.

\section{The effect of digital electronics of energy res- olution}

We have performed a large number on the optimal parameters for use of High Purity Germanium detectors with Ortec DSPEC analysis system. The resolution was just one of the parameters which was examined for these detector systems. The ratio of the values for the FWHM for the DSPEC system to the value of the resolution for the analog systems - for a given counting rate - are shown in figure 1 .

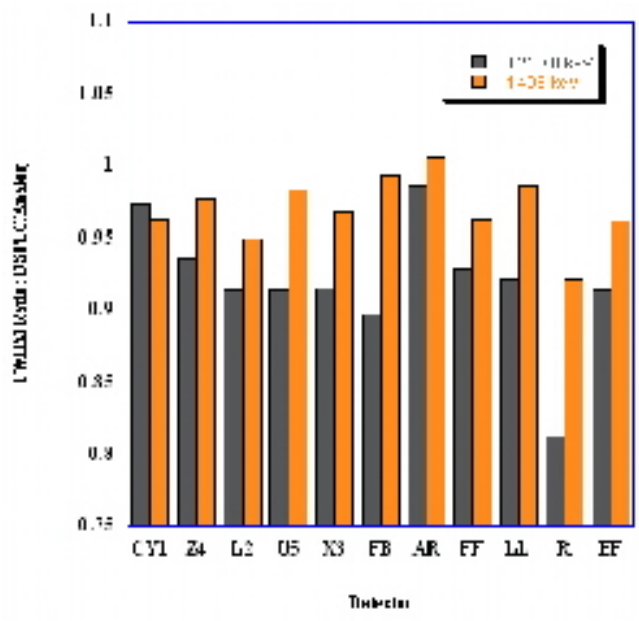

Figure 1: Ratio of the Full-Width Half Maximum (FWHM) for DSPEC to Analog electronics. 
As this figure shows there is a systematic trend for the DSPEC system to have a poorer resolution the system with the analog electronics. The average for this ratio for the $121.78 \mathrm{keV}$ measurement is $0.92 \pm 0.04$; while the average for the ratio at $1408 \mathrm{keV}$ is $0.97 \pm 0.02$. The difference in the resolution for the digital and analog system is on the order of 3-8 percent depending on the energy of the incident gamma ray.

This trend is consistent with the intuitive understanding the difference in the two different systems. In general, you would expect to get better results with the analog system because of the electronics take in account the entire signal that is outputted from the detector preamp. The energy resolution is very sensitive to the proper analysis of the entire preamp waveform.

The digital system can be made to produce results that should be very close to the results of the analog system but there are performance and economic implications in the design of the analysis system. The second of these concerns are not a realistic issue because the development of the equipment has already occurred in the case of the DSPEC. In principle, most of the digital analysis systems were developed to increase the dynamic range of the spectrometry system in terms of increasing the counting rate in the system without distortion of the peak characteristics. Most digital spectrometry systems - including the DSPEC - have been successful in accomplishing this goal but fall short of the high-fidelity of an analog system. This a design choose that most manufacturers make.

The data shown in figure 1 indicates the that there is poorer performance for the digital system compared to the analog system; the question that needs to be asked is whether this difference will limit the ability of analysis packages, like Pu600 to give reasonable results for the spectrometric data that they are trying to obtain. The answer to this question is two-fold. First, the results from the commercial digital systems will always be poorer than those from analog systems, for given set of analysis parameters. The corollary to this statement is that the analysis may be "good enough" for all applications in the area of international treaties where "one percent" precision is not required. Second, the analysis may be improved by doing a detailed analysis of the obtained peak shapes. ${ }^{1}$

It should be pointed out that in addition to the widening of the peaks by using the digital analysis hardware the shapes are distorted by an increase in the low energy tail associated with the peaks. The increase in the low energy tail is the result of inadequately digitizing the preamp signal because of the approximations that have to be made in the digital analyzer. The increase in the low energy tailing does not effect the analysis of the signal if the tailing is taken into account. Certainly, the peak shape parameters that have been used for the analog systems cannot be used for the analog systems. This is

\footnotetext{
${ }^{1}$ In principle this is an exercise that needs to be performed when new hardware is introduced into a spectrometry system. However, we have established a generic response function that we have used with Pu600 for a wide variety of HPGe detectors from 15 to 110 percent efficiency and with a wide variety of plutonium sources. This generic response function yields good results for all the detection systems that we have tested for a wide variety of source types.
} 
particularly the case when one deals with the de-convolution of closely spaced multiplets.

\section{Conclusions and recommendations for use of Pu600 with digital electronics}

Using digital electronics for the processing of signals from gamma detection systems is certainly the wave of the future. In particular, it is difficult to obtain robust analog systems. The use of digital electronics for the processing of High Purity Germanium detector signals does broaden the observed peak shape. In addition, the observed peaks have a larger low energy tail.

The digital systems have the advantage that they possess a larger dynamic range when dealing with counting rates. The performance of the digital systems in terms of the obtained peak shapes does not adversely effect the analyzability of the gamma ray pulse height distribution if the peaks shapes are properly taken into account.

It is our recommendation that digital processing electronics can be used without significant degradation of the Pu600 software to obtain good results for the isotopic measurements. However, a prestart measurement campaign will have to occur to get a suitable peak parameter set for the new digital spectrometry systems. The resulting "new canonical" peak parameters will be used in the Pu600 analysis code with good results. 